\title{
AVALIAÇÃO DO CONTROLE DE QUALIDADE EM ENSAIOS DE INTEGRIDADE EM ESTA- CAS HÉLICE CONTÍNUA
}

\section{Érica Pereira Affonso Guedes}

Mestranda em Engenharia Civil (Geotecnia) pela Universidade do Estado do Rio de Janeiro (UERJ), Engenheira Civil pelo Centro Federal de Educação Tecnológica Celso Suckow da Fonseca (CEFET/RJ).

epaguedes@gmail.com

\section{Jéssica Costa Marotti}

Mestranda em Engenharia Civil (Geotecnia) pela Pontifícia Universidade Católica do Rio de Janeiro (PUC-RJ), Engenheira Civil pelo Centro Federal de Educação Tecnológica Celso Suckow da Fonseca (CEFET/RJ)

jessica-marotti@hotmail.com

\section{Adriano de Lima Souza}

Mestrando em Engenharia Civil (Geotecnia) pela Pontifícia Universidade Católica do Rio de Janeiro (PUC-RJ), Engenheiro Civil pelo Centro Federal de Educação Tecnológica Celso Suckow da Fonseca (CEFET/RJ)

Isadriano@outlook.com.br

\section{Andréa Sousa da Cunha Fernandes}

Mestre em Ciências pela UFRJ, Rio de Janeiro, RJ, Brasil Professora do Departamento de Engenharia Civil - CEFET/RJ andreascunha@gmail.com

\section{RESUMO}

O presente artigo aborda a importância da execução do ensaio Pile Integrity Test (PIT) para verificação da integridade de estacas, bem como a correlação da qualidade de pre- 
paro do elemento para o ensaio e o sinal correspondente a uma estaca sem variação de impedância. O estudo de caso relata a execução de ensaios PIT realizados no primeiro semestre de 2016 em 247 estacas do tipo hélice contínua de um mesmo empreendimento. Após os ensaios nestes elementos, solicitou-se nova execução das estacas que apresentaram variação de impedância no primeiro teste. Posteriormente, as estacas foram ensaiadas novamente para averiguação do impacto do preparo dos elementos na qualidade do sinal obtido.

PALAVRAS-CHAVE: Ensaio de Integridade em Estaca. Fundações Profundas. Controle de Qualidade.

\title{
EVALUATION OF QUALITY CONTROL IN INTEGRITY TESTS ON CONTINUOUS FLIGHT AUGER PILES
}

\begin{abstract}
The present article addresses the relevance of pile integrity test (PIT) execution to verify the integrity of the foundation element as well as correlating the quality of pile's preparation to the test and its corresponding signal. The case study relates the execution of PIT tests performed in the first semester of 2016 in 247 continuous flight auger piles. After testing these elements, it was required to prepare again the piles that presented impedance variation on the first test. Posteriorly, the piles were tested once again to verify the impact of its preparation on the signal quality.
\end{abstract}

KEYWORDS: Pile Integrity Test. Deep Foundations. Quality Control.

\section{INTRODUÇÃO}

As fundações são estruturas de suma importância para a construção de um empreendimento, pois são elas as responsáveis pela transmissão das cargas da edificação para o solo. Assim, após a campanha de investigação geotécnica, são projetadas as fundações baseadas nas cargas provenientes da estrutura, da estratigrafia do solo local e do 
orçamento destinado à sua execução.

Para a garantia da obediência aos padrões de qualidade exigidos, no caso do uso de estacas, é utilizado o ensaio conhecido como PIT. Esse teste é realizado a partir do impacto de um martelo na cabeça da estaca instrumentada com um acelerômetro. O golpe gera uma onda de tensão que se propaga por todo o fuste do elemento com uma velocidade que depende das características do material da estaca. Ao se propagar, a onda sofre reflexões em seu percurso. Essas reflexões devem ser analisadas, podendo significar variação do material da estaca (como intrusão de solo no concreto ou vazios significativos no elemento).

Para a aquisição de sinais menos dispersos e mais confiáveis, deve-se preparar o topo da estaca de modo que o mesmo se apresente plano, sem concreto de má qualidade ao redor e sem umidade. O estudo relaciona o impacto que o preparo do elemento pode apresentar no resultado final do ensaio.

\section{JUSTIFICATIVA E METODOLOGIA}

A abordagem do referido tema é de extrema importância para a área da engenharia civil atualmente. Com o detrimento da qualidade de diversas construções, faz-se necessário o controle e fiscalização cada vez maior, desde a etapa de projeto até a execução. $\mathrm{O}$ atual estudo pretende analisar a importância que o correto preparo das estacas para o ensaio PIT tem no resultado final do teste, almejando a contribuição positiva para o processo de melhoria do controle de qualidade.

Para o estudo de caso, foram analisados os ensaios realizados em 2016 em 247 estacas do tipo hélice contínua - obtidos através do equipamento PIT (Pile Integrity Tester) em obra de uma termelétrica. As estacas que apresentaram resultados insatisfatórios foram reensaiadas após nova preparação das mesmas com o objetivo de comparar o impacto de um preparo adequado com a qualidade do sinal obtido.

\section{REFERENCIAL TEÓRICO}




\subsection{Execução de Estacas Hélice Continua}

As estacas do tipo hélice contínua foram desenvolvidas nos Estados Unidos na década de 80, tendo sido executadas pela primeira vez no Brasil em 1987. São elementos moldados in loco a partir da cravação de uma hélice no terreno até a cota de projeto por meio de torque apropriado para combater a resistência do solo local. Ao se alcançar a profundidade desejada, bombeia-se concreto por meio de um tubo central ao passo que a hélice é retirada. Por fim, introduz-se a armação em forma de gaiola por gravidade ou com auxílio de vibrador, conforme metodologia ilustrada na Figura 1 (ANTUNES e TAROZZO, 1998).

Figura 1 - Execução de estaca tipo hélice contínua

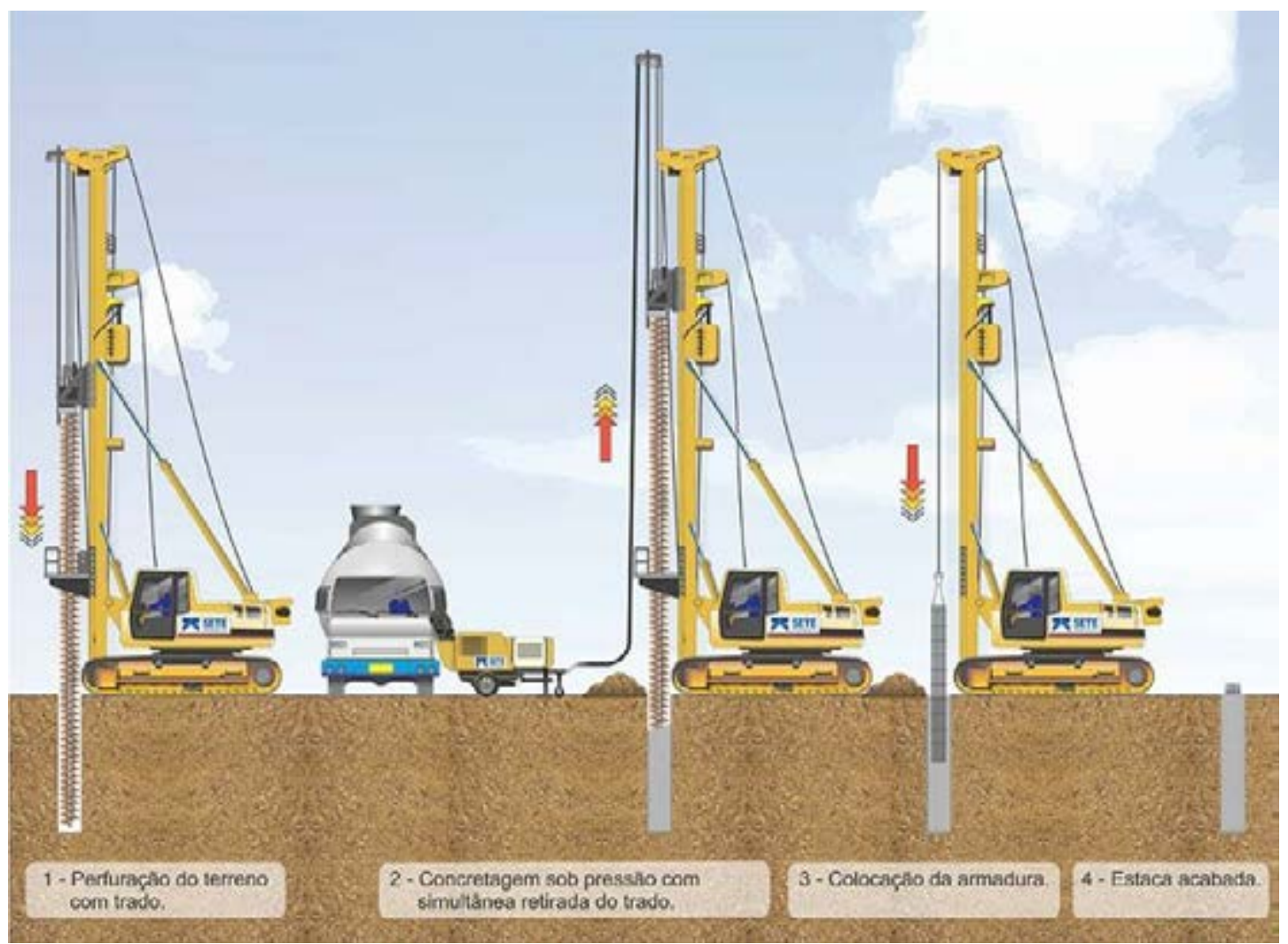

Fonte: (SETE ENGENHARIA, 2018) 
Antunes e Tarozzo (1998) observam que o controle executivo das estacas hélice continua é realizado a partir de equipamento eletrônico munido de sensores que verificam a profundidade na ponta do trado relacionada ao nível do terreno, velocidade de rotação da mesa, volume de concreto bombeado, pressão de concreto, inclinação da torre e torque.

3.2 Ensaio de Integridade (PIT)

O método PIT (Pile Integrity Test) é um procedimento para determinação da integridade de fundações profundas frequentemente utilizado em estacas moldadas in loco e pré-moldadas de concreto. O ensaio permite verificar a existência de dano ou falha estrutural ao longo do fuste e, em alguns casos, confirmar o comprimento da estaca ensaiada.

Antes do ensaio, as estacas geralmente são arrasadas e regularizadas, com seu topo nivelado e limpo, e seu fuste sem concreto de má qualidade ao redor (Figura 2). Outro fator determinante para o sucesso do ensaio é a ausência de chuva, já que a umidade no topo da estaca pode interferir nos sinais gerados durante o ensaio (CINTRA et al., 2013). 
Figura 2 - Exemplo da correta preparação para o ensaio PIT

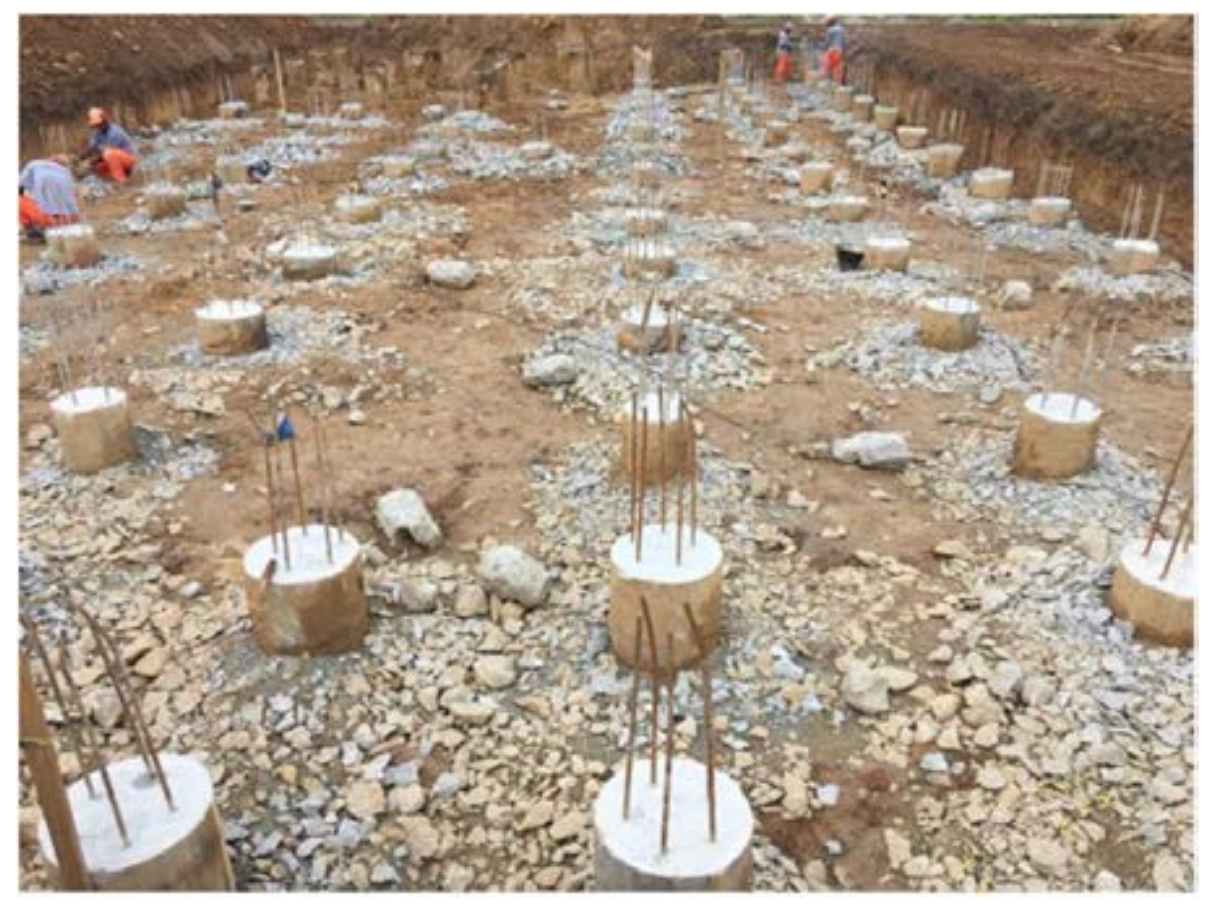

Fonte: (AUTORES, 2016)

Com a estaca devidamente preparada, é instalado um acelerômetro no topo do elemento (fixado por uma resina) e, em seguida, aplicam-se sucessivos golpes com um martelo instrumentado ou não (Figura 3). Os golpes geram ondas que trafegam ao longo da estaca, e sofrem reflexões ao encontrar qualquer variação nas características do material, tais como: estrangulamento do fuste da estaca, nichos de concretagem, fissuras e trincas. 
Figura 3 - Esquema de ensaio PIT

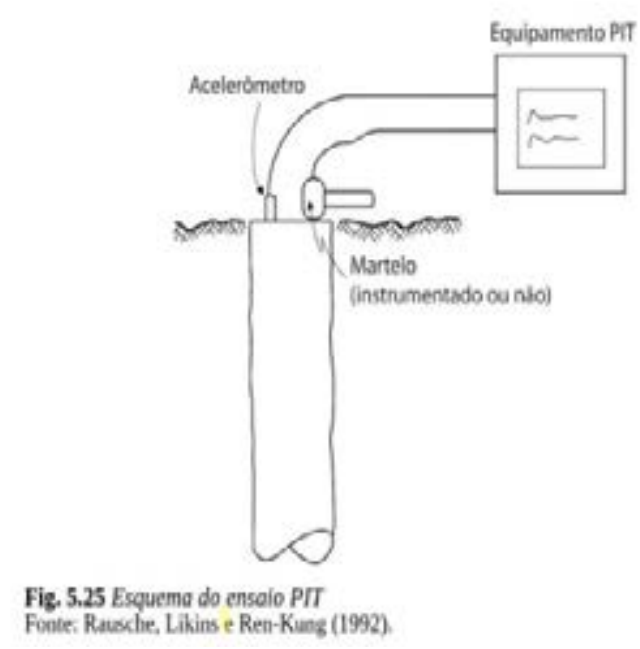

Fonte: (Rausche et al.1992)

O ensaio é baseado nas reflexões da onda de tensão, causadas pela variação na impedância da estaca, definida pela Equação 1:

Onde,

Z = Impedância;

$\mathrm{E}=$ Módulo de elasticidade do material;

A = Área da seção;

$c=$ Velocidade de propagação da onda.

Os sinais obtidos pelo acelerômetro são enviados para uma unidade eletrônica portátil para processamento e armazenamento dos dados (Figura 4). Estes são transferidos para o computador onde são analisados, com o auxílio do software PIT-W, para obtenção do diagnóstico. 
Figura 4 - Aparelho PIT

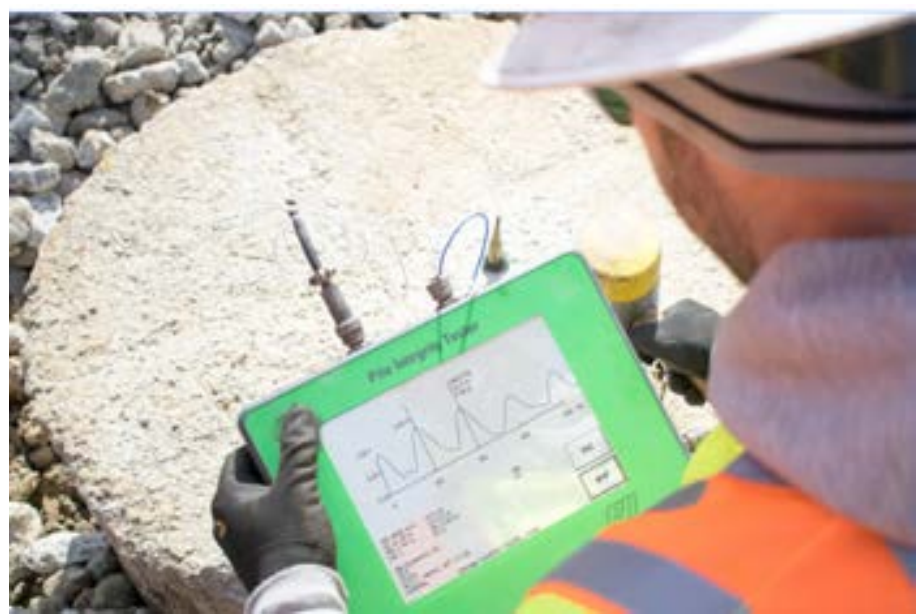

Fonte: (PILE, 2019)

Na Figura 5, observa-se a comparação entre dois sinais obtidos através do ensaio de PIT. Em ambos os sinais há uma reflexão significativa no início da estaca e uma no final. A primeira grande variação da velocidade refere-se a cabeça da estaca e a última refere-se a ponta. Percebe-se, assim, que essa estaca tem cerca de 25 metros. Com exceção da reflexão de topo e ponta, a parcela do sinal que está acima da linha tracejada significa estreitamento de seção e a parcela abaixo, alargamento (CINTRA et al., 2013). 
Figura 5 - Registro de velocidade no ensaio PIT em uma estaca danificada e em uma íntegra

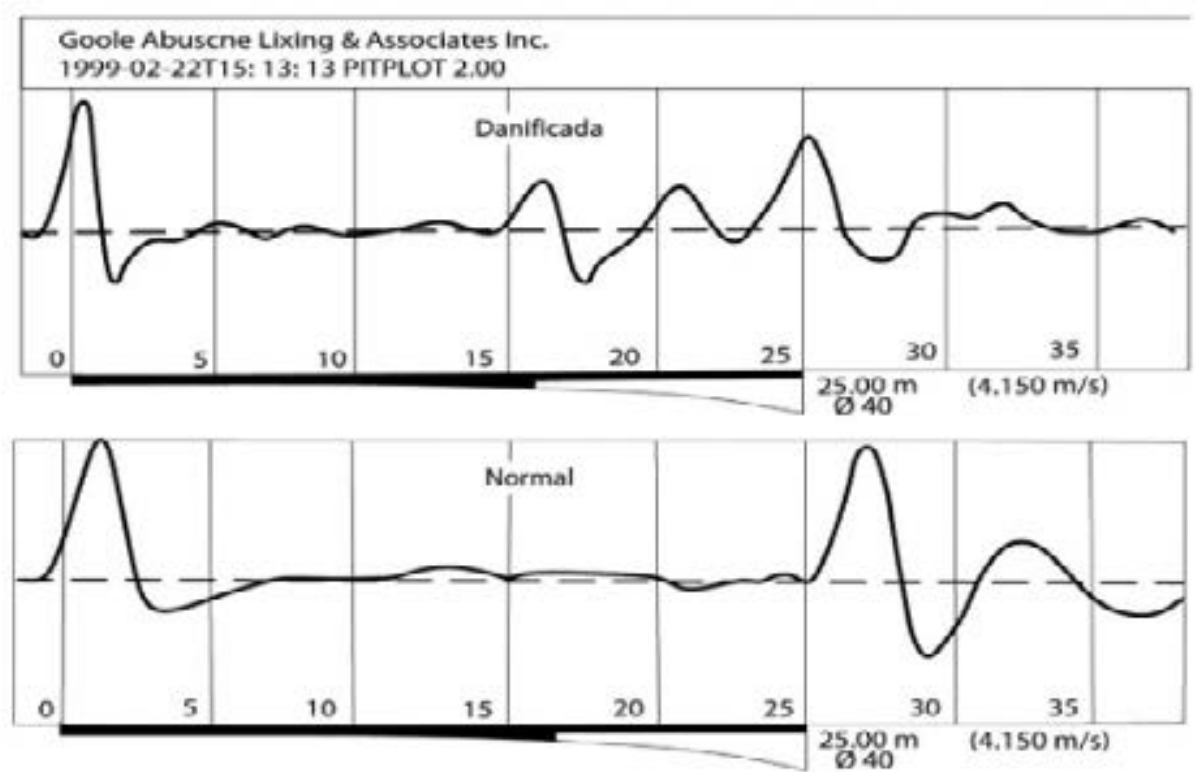

Fig. 5.28 Registro de velocidade no ensaio PIT de uma estaca danificada e de uma estaca normal

Fonte: Likins et al. (2000).

Fonte: (LINKINS et al., 2000)

Uma mudança significativa no sinal de velocidade pode ser atribuída a variações de impedância, porém variações menores no sinal podem ser causadas pela resistência do solo ao redor da estaca (por isso, recomenda-se a utilização das sondagens mais próximas ao local para o auxílio na interpretação dos resultados). Sendo assim, no primeiro sinal ilustrado na Figura 5 encontra-se um dano localizado a aproximadamente 15 metros de estaca. Tal anomalia pode ser verificada devido a repentina reflexão de onda com alta amplitude, o que não ocorre no segundo sinal, referente a uma estaca íntegra (LINKINS et al., 2000).

Vale ressaltar que o referido ensaio não tem função de aprovar ou condenar a fundação da obra quanto a sua capacidade de carga. Por isso, sua análise não deve ser usada como único fator para determinação da aceitação ou rejeição da estaca. 


\section{ESTUDO DE CASO}

Inicialmente, foi realizado um levantamento dos ensaios realizados entre janeiro e março de 2016 para o empreendimento em questão - a escolha do estudo nesta obra se deu devido a quantidade de ensaios de integridade que foram realizados em pouco tempo, bem como as semelhanças das características das estacas. Para tal, utilizou-se uma tabela de controle de serviços executados preexistente, onde constava a quantidade de ensaios e os dados da obra. De posse desses dados, foram analisados os relatórios referentes a cada ensaio, o que proporcionou, além da confirmação das quantidades citadas anteriormente, o diagnóstico de cada teste. Posteriormente, elaborou-se uma planilha correlacionando a quantidade de ensaios e o seu respectivo diagnóstico.

Como resultado da etapa de levantamentos de dados, foram mapeadas 247 estacas do tipo hélice contínua ensaiadas no local, com diâmetro variando entre 40 e $60 \mathrm{~cm}$ e comprimento entre 9 e 23,5 metros.

A partir dos resultados obtidos, foi observado que, das 247 estacas ensaiadas, 38 apresentaram variação de impedância - cerca de $15 \%$ do total dos elementos testados (Gráfico 1). Ao perceber a quantidade significativa de estacas não conformes, foi solicitada a repetição das estacas que apresentaram variação de impedância.

\section{Gráfico 1 - Amostragem}

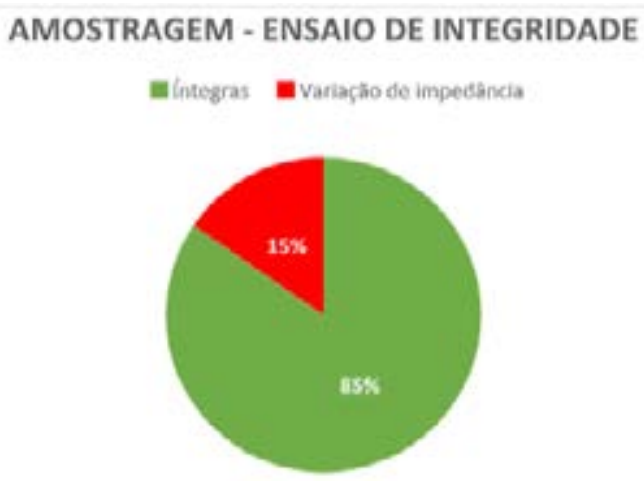

Fonte: (AUTORES, 2016) 
Para repetir o ensaio, foram requisitados novo arrasamento e um melhor preparo da cabeça das estacas para que fossem eliminadas possíveis interferências ocasionadas pelo seu mau preparo ou pela existência de algum concreto de má qualidade próximo ao topo do elemento de fundação.

Após os ensaios serem repetidos em 22 das 38 estacas que apresentaram não conformidade, verificou-se que 17 estavam íntegras (77\%) e apenas $5(23 \%)$ estavam não conformes Gráfico 2).

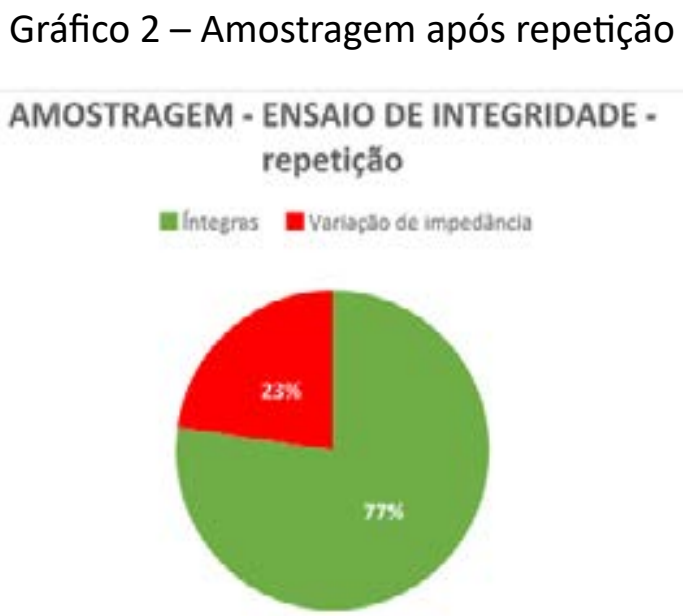

Fonte: (AUTORES, 2016)

\section{CONSIDERAÇÕES FINAIS}

Por meio deste trabalho, foi possível apresentar o ensaio de integridade em estacas, bem como verificar a relevância da preparação das estacas obtenção de melhores resultados no teste.

Muitas obras, devido ao cronograma corrido, negligenciam a parte de controle de qualidade. Embora o ensaio de integridade seja de rápida execução, o processo de análise do sinal demanda mais atenção e cuidado. No caso de estacas moldadas in loco, a análise deve ser ainda mais cautelosa, pois nesse tipo de fundação as variações de se- 
ção são comuns devido ao seu método construtivo. Cabe ao responsável a distinção de quais reflexões de onda são comum a aquela fundação e quais estão relacionadas à possíveis variações de impedância. O ensaio PIT torna-se, assim, um indicador fundamental para a análise da integridade de estacas, estabelecendo ao construtor maior segurança perante a execução das fundações.

Conforme apresentado neste estudo, um dos fatores fundamentais para assegurar a qualidade do ensaio é o preparo correto da cabeça da estaca. A preparação compreende a remoção de concreto de má qualidade do redor do elemento e seu topo plano e livre de umidade. Durante a construção de uma termelétrica - obra em questão deste trabalho - foram analisados 247 ensaios de integridade realizados entre janeiro e março de 2016. Esses testes foram realizados em estacas com preparação deficiente. Dessas estacas, 38 apresentaram variação de impedância - o que implicaria no diagnóstico desfavorável para as mesmas. Foi possível preparar corretamente 22 estacas para a repetição do ensaio. Após a análise dos sinais, foi constatado que $77 \%$ desses elementos seriam avaliados como não conformes devido a uma preparação inadequada, que não refletia na real condição das estacas.

Percebe-se, assim, que a correta preparação dos elementos se apresenta de maneira fundamental para a obtenção de um bom resultado no ensaio. A necessidade de repetição de ensaios, além de encarecer os testes, retarda o diagnóstico, atrasando, por conseguinte, o cronograma da obra.

\section{REFERÊNCIAS}

ANTUNES, W. R.; TAROZZO, H. Fundações: Teoria e prática, Cap.9. 2ạ. ed. São Paulo: Pini, 1998.

CINTRA, J. C. A.; AOKI, N.; TSUHA, C. H. C.; GIACHETI, H. L. Fundações: Ensaios Estáticos e Dinâmicos. 1.ed. São Paulo: Oficina de Textos, 2013. 
LIKINS, G.; PISCSALKO, G.; RAUSCHE, F.; MORGANO, C. M. Detection and prevention of anomalies for augercast pilling. In: NIYAMA, S.; BEIM, J. (Ed.). Aplication of Stress-wave theory to piles: quality assurance on land and offshore pilling: proceedings of the sixth international conference. São Paulo: A. A. Balkema, 2000.

PILE, 2019. Disponível em: < https://www.pile.com/products/pit/>. Acesso em: 22 Agosto 2019.

RAUSCHE, F.; LIKINS. G. E.; REN-KUNG. S. “Pile integrity testing and analysis”. Proceedings of the Fourth International Conference on the Application of Stress-Wave Theory to Piles: The Netherlands, (1992).

SETE ENGENHARIA, 2018. Disponível em: <http://www.fundacoessete.com.br/>. Acesso em: 12 Setembro 2018. 